\title{
PREVALENCE OF HEPATIC ARTERIAL VARIATIONS WITH IMPLICATIONS IN PANCREATODUODENECTOMY
}

\author{
Prevalência de variações arteriais hepáticas com implicações em pancreatoduodenectomia
}

Silvio Marcio Pegoraro BALZAN ${ }^{1,2,3}$, Vinicius Grando GAVA 3 , Sabrina PEDROTTI', Marcelo Arbo MAGALHÃES ${ }^{2}$, Alex SCHWENGBER ${ }^{1,2}$, Marcelo Luiz DOTTO' ${ }^{1,2}$, Carmela Reckziegel KREBS ${ }^{4}$

\begin{abstract}
How to cite this article: Balzan SMP, Gava VG, Pedrotti S, Magalhães MA, Schwengber A, Dotto ML, Krebs CR. Prevalence of hepatic arterial
\end{abstract} variations with implications in pancreatoduodenectomy. ABCD Arq Bras Cir Dig. 2019;32(3):e1455. DOI: /10.1590/0102-672020190001e1455

From the 'Departamento de Biologia e Farmácia, Curso de Medicina, Universidade de Santa Cruz do Sul, Santa Cruz do Sul; 2Instituto de Oncologia Saint Gallen, Cirurgia Hepatobiliopancreática, Santa Cruz do Sul; ${ }^{3}$ Hospital Moinhos de Vento, Centro de Oncologia Lydia Wong Ling, Porto Alegre; ${ }^{4}$ Radson, Hospital Ana Nery, Santa Cruz do Sul ('Department of Biology and Pharmacy, Medicine Course, University of Santa Cruz do Sul, Santa Cruz do Sul; ${ }^{2}$ Institute of Oncology Saint Gallen, Hepatobiliary-pancreatic Surgery, Santa Cruz do Sul; ${ }^{3}$ Hospital Moinhos de Vento, Oncology Center Lydia Wong Ling, Porto Alegre; ${ }^{4}$ Radson, Ana Nery Hospital, Santa Cruz do Sul), RS, Brazil

HEADINGS - Pancreaticoduodenectomy. Hepatic artery. Pancreatic neoplasms.
ABSTRACT - Background: Pancreaticoduodenectomy is the usual surgical option for curative treatment of periampullary cancer and carries a significant mortality. Arterial anomalies of the celiac axis are not uncommon and might lead to iatrogenic lesions or requiring arterial resection/ reconstruction in a pancreatoduodenectomy. Aim: Determine the prevalence of arterial variations having implications in pancreatoduodenectomy. Methods: Celiac trunk and hepatic arterial system anatomy was retrospectively evaluated in 200 abdominal enhanced computed tomography studies. Results: Normal anatomy of hepatic arterial system was found in $87 \%$ of cases. An anomalous right hepatic artery was identified in $13 \%$ of cases. In 12 cases there was a substitute right hepatic artery arising from superior mesenteric artery and in two cases an accessory right hepatic artery with similar origin. A hepatomesenteric trunk was identified in seven cases and in five there was a right hepatic artery directly from the celiac trunk. All cases of anomalous right hepatic artery had a route was behind the pancreatic head and then, posteriorly and laterally, to the main portal vein before reaching the liver. Conclusions: Hepatic artery variations, such as anomalous right hepatic artery crossing posterior to the portal vein, are frequently seen (13\%). These patients, when undergoing pancreatoduodenectomy, may require a change in the surgical approach to achieve an adequate resection. Preoperative imaging can clearly identify such variations and help to achieve a safer pancreatic head dissection with proper surgical planning.

\section{Correspondence: \\ Silvio Marcio Pegoraro Balzan \\ E-mail: sbalzan@hotmail.com}

Financial source: none

Conflict of interest: none

Received for publication: 03/01/2019 Accepted for publication: 12/04/2019

DESCRITORES - Pancreaticoduodenectomia. Artéria hepática. Neoplasias pancreáticasReganho de peso.
RESUMO - Racional: Pancreatoduodenectomia consiste no procedimento cirúrgico usual para tratamento curativo de neoplasias periampulares e apresenta mortalidade significativa. Variações arteriais do tronco celíaco não são incomuns e podem favorecer lesões iatrogênicas ou exigirem realização de ressecção/reconstrução arterial durante pancreatoduodenectomia. Objetivo: Determinar a prevalência de variações arteriais que apresentam implicações durante pancreatoduodenectomia. Métodos: A anatomia do tronco celíaco e sistema arterial hepático foi investigada retrospectivamente em 200 exames tomográficos contrastados do abdome. Resultados: Anatomia normal do sistema arterial hepático foi observada em $87 \%$ dos casos. Presença de uma artéria hepática direita anômala foi identificada em 13\%. Em 12 casos houve uma artéria hepática direita substituta originária da artéria mesentérica superior, em dois uma artéria hepática direita acessória com origem similar. Tronco hepaticomesentérico foi identificado em sete casos e em cinco houve uma artéria hepática direita originária diretamente do tronco celíaco. Em todos casos de artéria hepática direita anômala seu curso foi por trás da cabeça do pâncreas e com trajeto passando posteriormente ao tronco da veia porta e após percorrendo sua face lateral direita antes de alcançar o fígado. Conclusões: Variações arteriais hepáticas, como artéria hepática direita anômala com trajeto posterior à veia porta, são frequentes (13\%). Nestes pacientes, quando submetidos à pancreatoduodenectomia, pode ser necessária alteração na abordagem cirúrgica para ressecção adequada. Exames de imagem préoperatórios podem claramente identificar estas variações e auxiliar na realização de dissecção segura da cabeça do pâncreas com adequado planejamento cirúrgico.
S urgical resection remains the only potentially curative treatment for cancer of the head of the pancreas, and pancreatoduodenectomy (PD) is the standard surgical option $n^{8,10}$. Despite technical advances, PD remains a challenging operation with surgical mortality rates ranging from $1-6 \%$ even at experienced centers $17,19,217,10$. Major vessels involvement around the pancreas can make the surgery even more challenging ${ }^{4,6,23}$ especially if arterial resection and reconstruction are necessary $1,13,14,16$. Arterial anomalies of the celiac axis, mainly of hepatic arteries, are not uncommon. These variations can result in arterial involvement of the anomalous artery by the tumor and increase the risk of vascular injury. Thus, awareness of patient vascular anatomy is important to avoid iatrogenic injury while performing a safe pancreatic head resection.

The purpose of this study was to determine the prevalence of arterial variations that 
can lead to iatrogenic injury or require resection/reconstruction during a PD.

\section{METHOD}

\section{Patients}

Two hundred consecutive patients were submitted to contrast enhanced abdominal computed tomography (CT) in a tertiary radiology unit. CTs were retrospectively analyzed. Patients with a previous history of major upper abdominal surgery, a large abdominal mass that distorted the celiac or its branches, and those younger than 18 years old were excluded. This study was submitted and approved by the institutional ethics committee (number 2.755.349) and registered at Plataforma Brasil.

\section{Image technique and interpretation}

The CT images were obtained with the use of a spiral 16-detector row scanner (LightSpeed Ultra Scanner, GE Medical Systems). Section thicknesses of $3.0 \mathrm{~mm}$ or less was used. Dynamic images were obtained after endovenous injection of iopromide through an 18-gauge plastic catheter placed in an antecubital vein. The hepatic arterial phase scanning delays 9-15 seconds after descending aorta enhancement of 100 Housfied Units (HU). Total contrast medium volume used ranged from 1-1.5 ml per $\mathrm{kg}$ of body weight. Hepatic arterial, portal venous, and equilibrium phases were routinely achieved. Dicom images were analyzed by a radiologist and a hepatobiliarypancreatic surgeon using a free open source medical image viewer (Horos 3.3.1 for MacOS, Horos project, 2018).

\section{Arterial anomalies}

Standard arterial anatomy was considered as: the common hepatic artery originating from celiac trunk and being called proper hepatic artery after giving the gastroduodenal artery. Right and left hepatic arteries originating from proper hepatic artery. The presence of a right hepatic artery (RHA) (replaced or accessory) or a common hepatic artery originating from the superior mesenteric artery are known arterial anomalies that require special caution and/or technical modifications during PD. These variations were searched in each tomographic study and recorded in schematic figures. The Hiatt classification was adopted to evaluate arterial anatomical variations ${ }^{9}$.

\section{RESULTS}

A total of 214 patients were initially screened from June to August 2018 in a tertiary radiology unit. There were 14 exclusions due to large abdominal tumors (four cases of abdominal neoplasms and one of polycystic hepatic disease) distorting the celiac trunk and 10 exclusions due to major upper abdominal surgery (five pancreatic resection and other five major hepatic resection). The distribution of men and women was similar (93 and 107, respectively).

A normal RHA originating from the main trunk of the proper hepatic artery (Figure $1 \mathrm{~A}$ ) was found in 174 cases (87\%). An aberrant RHA was identified in 26 (13\%). Among these 26 cases of aberrant RHA, 12 (6\%) were a replaced RHA arising from SMA (Figure $1 \mathrm{~B}$ and Figure 2), two (1\%) were an accessory RHA arising from SMA (Figure $1 \mathrm{C})$, seven (3.5\%) the origin of the hepatic artery was a hepatomesenteric trunk (Figure 1D), and five (2.5\%) the RHA was replaced with its origin directly from celiac trunk (Figure 1E). All aberrant RHA (13\%) had a route behind the head of the pancreas and then, posteriorly and laterally, to the main portal vein before reaching the liver.
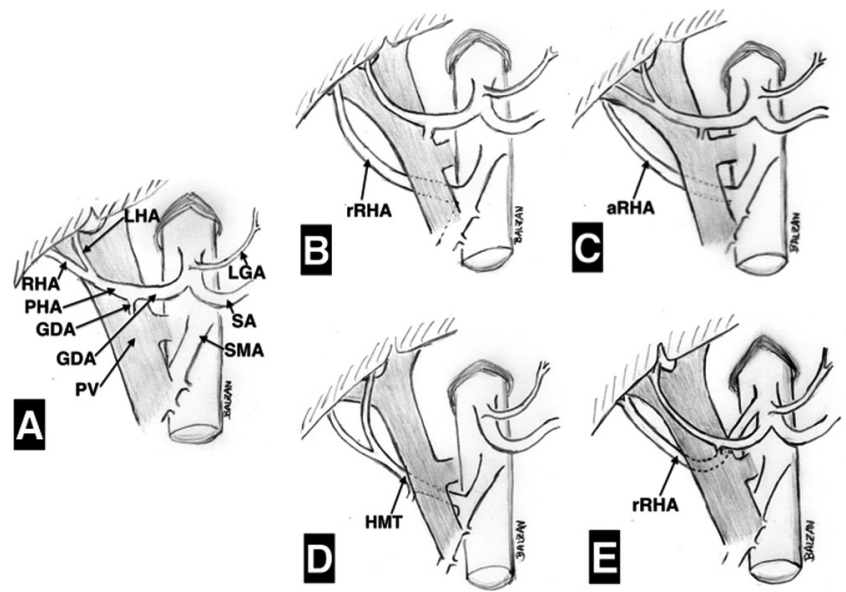

$\mathrm{LHA}=$ left hepatic artery; $\mathrm{RHA}=$ right hepatic artery; $\mathrm{PHA}=$ proper hepatic artery; $\mathrm{GDA}=$ gastroduodenal artery; $\mathrm{PV}=$ portal vein; $\mathrm{LGA}=$ left gastric artery; $\mathrm{SA}=$ splenic artery; $\mathrm{SMA}=$ superior mesenteric artery; $\mathrm{rRHA}=$ replaced right hepatic artery; aRHA=accessory right hepatic artery; $\mathrm{HMT}=$ hepatomesenteric trunk

FIGURE1 - Diagrammatic representation of hepatic arterial system variations with implications in pancreatoduodenectomy observed in 200 reviewed cases. Variations of left hepatic artery $(n=7)$ are not shown: A) standard arterial configuration; $\mathrm{B}$ ) replaced right hepatic artery from superior mesenteric artery (prevalence $6 \%) ;$ C) accessory right hepatic artery from superior mesenteric artery (prevalence 1\%); D) right hepatic artery from hepatomesenteric trunk (prevalence 3.5\%); and E) replaced right hepatic artery directly from celiac trunk with retroportal course (prevalence 2.5\%).

Additionally, eight cases (4\%) of aberrant left hepatic artery were identified. In seven cases the left hepatic artery (replaced in four cases and accessory in three) arose from the left gastric artery. In one case a replaced left hepatic artery came directly from aorta. The course of these aberrant left hepatic arteries was far from head of the pancreas. In one of the reported cases there was an association of accessory left hepatic artery and replaced right hepatic artery. Also, there was one case celiac trunk and superior mesenteric artery arising from a common trunk from aorta.

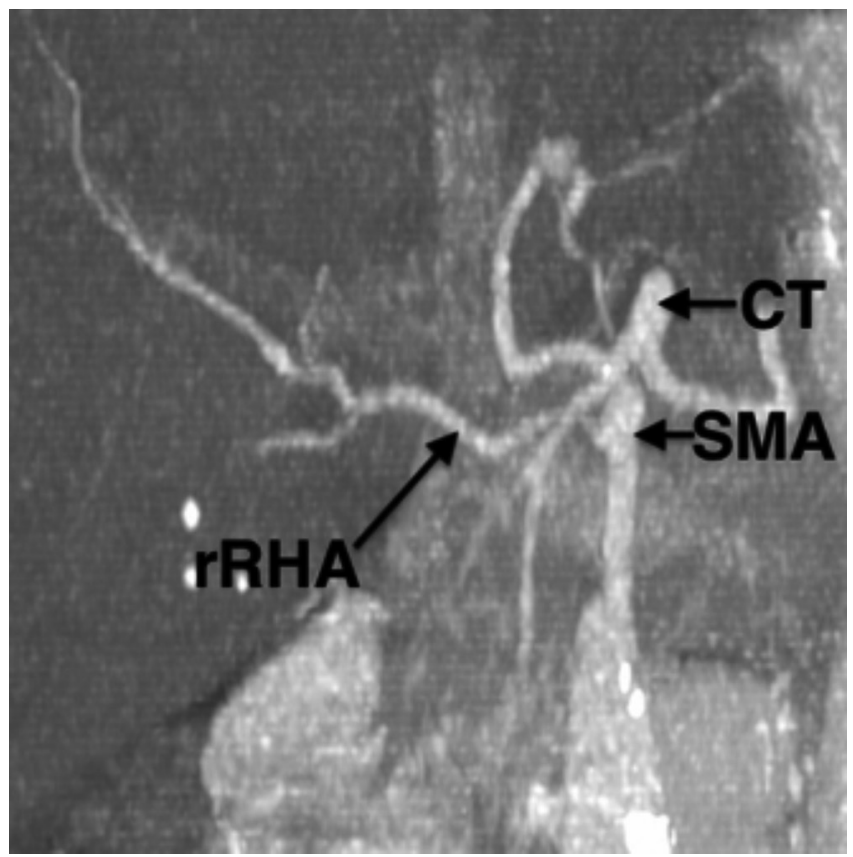

FIGURE 2 - Replaced right hepatic artery (rRHA) arising from superior mesenteric artery (SMA). CL=celiac trunk. 


\section{DISCUSSION}

Following normal development, common hepatic artery arises from celiac trunk and it continues as the proper hepatic artery after giving origin to the gastroduodenal artery. Right and left hepatic arteries usually are branches of the proper hepatic artery. However, numerous anatomical arterial variations can result from anomalies of embryologic elements ${ }^{22}$. In fact, a "normal" or regular arterial pattern of arterial hepatic branches is reported with a frequency of $62.5 \%$ to $90.5 \%$ of cases $^{15,22,26}$. Some anatomical variations of hepatic arterial system have crucial importance in pancreatic head resections, such as $\mathrm{PD}^{2,11,18}$.

Since the initial PD description by Whipple et al. ${ }^{25}$ in 1935 , this complex procedure evolved and underwent several changes ${ }^{3}$. However, arterial anatomical variations remain a challenge. Ligation of a hepatic artery may result in hepatic necrosis, liver abscesses, ischemic biliary injury, and/or an anastomotic fistula. These are potential life-threatening complications ${ }^{13}$

A standard PD and its variations comprise at least dissection of common and proper hepatic arteries and gastroduodenal artery. This one is usually ligated and sectioned in its origin. Also, lymphadenectomy of the common hepatic artery and celiac trunk is frequently indicated in PD for cancer. Additionally, pancreatic arterial branches from superior mesenteric artery (such as inferior pancreatoduodenal arteries) are ligated during retroportal pancreatic lamina resection ${ }^{20}$.

Anomalous right hepatic artery originating from the superior mesenteric artery might show different relations with the pancreas and the portal vein. They are often in contact with the posterior aspect of the head of the pancreas and go lateral and posterior to the portal vein. Anomalous common hepatic artery arising from the SMA (known as the hepatomesenteric trunk) might have a similar course. An important finding of the present study is that in all cases of anomalous right hepatic artery, including those that arouse directly from SMA and also those from a hepatic-mesenteric trunk, run posterior to the pancreatic head and portal vein, and laterally to the portal vein before reaching the liver. These anomalous vessels might be accidentally damaged during PD and/or can be involved by tumors of the pancreatic head and cause intra-operative or postoperative bleeding. . $^{13,14}$

Identification of arterial variations allows proper planning and appropriate operative management in case of vascular encasement or arterial injury. Simple ligation and section should be avoided (except in cases of accessory vessels) due to the risk of hepatic necrosis and liver abscess. Despite of being technically demanding, dissection of the vessels far from the pancreas is usually possible without compromising the radicality of resection (Figure 3 ) and should be attempted ${ }^{2}$. Resection and reconstruction may be required in certain arterial variations (such as in case of intra-pancreatic course) or tumor encasement (Figure 4) 2,18. It has been demonstrated that the presence of a anomalous RHA in patients with pancreatic adenocarcinoma does not affect resectability. It is suggested that in patients with resectable pancreatic tumors the presence of this variation does not increase $\mathrm{R} 1$ rates and is not associated with worse postoperative outcomes or overall survival5,12,24. In most of cases of PD with an aberrant RHA it was possible to preserve this artery; resection and reconstruction was restricted to arterial encasement. For a while, it is not clear if arterial involvement of an aberrant RHA by a pancreatic tumor has the same clinical impact than involvement of other arteries (such as celiac trunk or common hepatic artery). Thus, resection of a tumor involved aberrant right hepatic artery might represent an acceptable option.

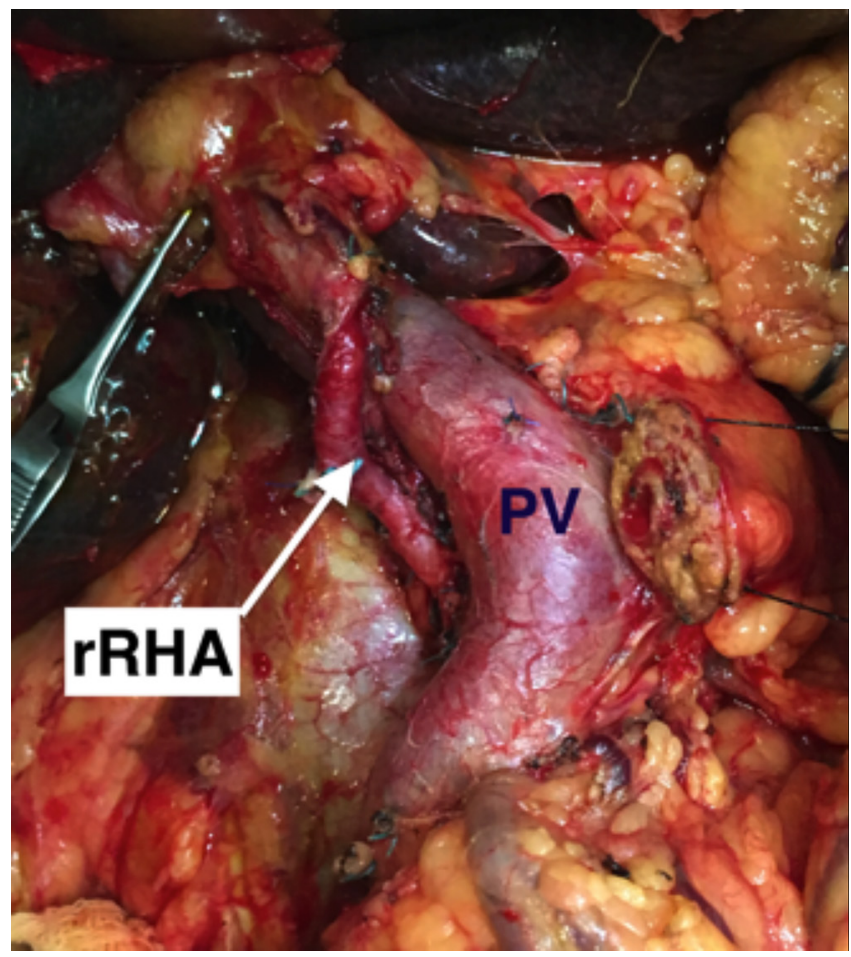

FIGURE 3 - Operative view showing dissection of a replaced right hepatic artery (rRHA)during a pancreatoduodenectomy: note the course of rRHA posterior to the portal vein $(\mathrm{PV})$ and then lateral to the PV.
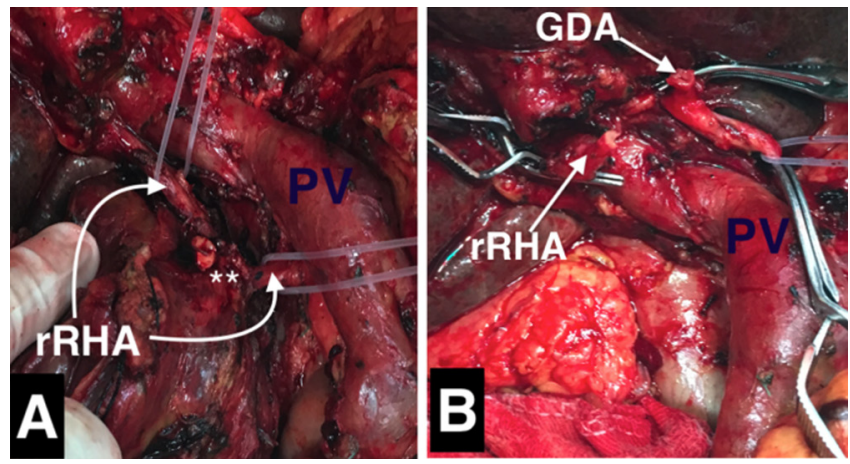

FIGURE 4 - Operative view during a pancreatoduodenectomy: A) note the presence of a replaced right hepatic artery ( $r R H A)$ from superior mesenteric artery, crossing posterior to the portal vein (PV) and involved by a pancreatic tumor (asterisks); B) segmental resection of the involved rRHA with distal segment prepared to be anastomosed with the stump of the gastroduodenal artery (GDA)

It was found an anomalous right hepatic artery (either an accessory or substitute RHA from SMA or a RHA from a hepatic-mesenteric trunk) in 26 cases (13\%), all of them with a course just posterior to the portal vein and in contact with the head of the pancreas. Additionally, were found two cases of a RHA directly from the celiac trunk, also with a retroportal course. These findings are accordance with the literature, with a $13-26 \%$ rate of anomalous $\mathrm{RHA}$ reported ${ }^{11,26}$.

The definition of the arterial vascular anatomy preoperatively or early during PD is crucial. It can avoid bleeding and postoperative complications due to arterial injury. Associated with the current imaging techniques, dissection of the superior mesenteric artery as an initial step of PD can be used very selectively. 


\section{CONCLUSION}

Hepatic artery variations, such as anomalous right hepatic artery crossing posterior to the portal vein, are frequently seen. These patients, when undergoing pancreatoduodenectomy, may require a change in the surgical approach to achieve an adequate resection. Preoperative imaging can clearly identify such variations and help to achieve a safer pancreatic head dissection with proper surgical planning.

\section{ORCID}

Silvio Marcio Pegoraro Balzan: 0000-0002-7164-8141

\section{REFERENCES}

1. Amano $\mathrm{H}$, Miura $\mathrm{F}$, Toyota $\mathrm{N}$, et al. Is pancreatectomy with arterial reconstruction asafeand useful procedureforlocallyadvanced pancreatic cancer? J Hepatobiliary Pancreat Surg. 2009;16(6):850-857. doi:10.1007/ s00534-009-0190-7.

2. ElAmrani M, PruvotF-R, Truant S. Management of the righthepatic artery in pancreaticoduodenectomy: a systematic review. J Gastrointest Oncol. 2016;7(2):298-305. doi:10.3978/j.issn.2078-6891.2015.093.

3. Are C, Dhir M, Ravipati L. History of pancreaticoduodenectomy: Early misconceptions, initial milestonesand the pioneers. HPB.2011;13(6):377384. doi:10.1111/j.1477-2574.2011.00305.x.

4. Cheung TT, Poon RTP, Chok KSH, et al. Pancreaticoduodenectomy with vascular reconstruction for adenocarcinoma of the pancreas with borderlineresectability. World JGastroenterol.2014;20(46):17448-17455. doi:10.3748/wjg.v20.i46.17448.

5. Eshuis WJ, Olde Loohuis KM, Busch ORC, van Gulik TM, Gouma DJ. Influence of aberrant right hepatic artery on perioperative course and longterm survival after pancreatoduodenectomy. HPB. 2011;13(3):161167. doi:10.1111/j.1477-2574.2010.00258.x.

6. Gong Y, Zhang L, He T, et al. Pancreaticoduodenectomy Combined with Vascular Resection and Reconstruction for Patients with Locally Advanced Pancreatic Cancer:AMulticenter, Retrospective Analysis. PLoS One. 2013;8(8). doi:10.1371/journal.pone.0070340.

7. Hartwig W, Werner J, Jäger D, Debus J, Büchler MW. Improvement of surgical results for pancreatic cancer. Lancet Oncol. 2013;14(11). doi:10.1016/S1470-2045(13)70172-4.

8. He C, Mao Y, Wang J, Duan F, Lin X, Li S. Nomograms predict long term survival for patients with periampullary adenocarcinoma after pancreatoduodenectomy. BMC Cancer. 2018;18(1):327. doi:10.1186/ s12885-018-4240-x

9. Hiatt JR, Gabbay J, Busuttil RW. Surgical anatomy of the hepatic arteries in 1000 cases. Ann Surg. 1994;220(1):50-52. http://www.ncbi.nlm.nih. gov/pubmed/8024358.

10. Kamisawa T, Wood LD, Itoi T, Takaori K. Pancreatic cancer. Lancet. 2016;388(10039):73-85. doi:10.1016/S0140-6736(16)00141-0.
11. KimJH,Gonzalez-HerediaR, DaskalakiD, RashdanM,MasrurM,Giulianotti PC. Totally replaced right hepatic artery in pancreaticoduodenectomy: is this anatomical condition a contraindication to minimally invasive surgery? HPB. 2016;18(7):580-585. doi:10.1016/j.hpb.2016.04.009.

12. Kim PTW, Temple $S$, Atenafu EG, et al. Aberrant right hepatic artery in pancreaticoduodenectomyforadenocarcinoma:impactonresectabilityand postoperative outcomes.HPB(Oxford).2014;16(3):204-211.doi:10.1111/ hpb.12120.

13. Kleive D, Sahakyan MA, KhanA, Fosby B, Line PD, Labori KJ. Incidence and management of arterial injuries during pancreatectomy. Langenbeck's Arch Surg. 2018:403(3):341-348. doi:10.1007/s00423-018-1666-1.

14. Landen S, Ursaru D, Delugeau V, Landen C. How to deal with hepatic artery injury during pancreaticoduodenectomy. A systematic review. J Visc Surg. 2017;154(4):261-268. doi:10.1016/j.jviscsurg.2017.05.013.

15. Marco-Clement I, Martinez-Barco A, Ahumada N, et al. Anatomical variations oftheceliactrunk:cadavericand radiological study. Surg Radiol Anat. 2016;38(4):501-510. doi:10.1007/s00276-015-1542-4.

16. Miyazaki M, Yoshitomi $\mathrm{H}$, Takano $\mathrm{S}$, et al. Combined hepatic arterial resection in pancreatic resections for locally advanced pancreatic cancer. Langenbeck's Arch Surg. 2017;402(3):447-456. doi:10.1007/ s00423-017-1578-5.

17. Narayanan S, Martin AN, Turrentine FE, BauerTW, Adams RB, Zaydfudim VM. Mortality after pancreaticoduodenectomy: assessing early and late causes of patient death. J Surg Res. 2018;231:304-308. doi:10.1016/j. jss.2018.05.075.

18. Noussios G, Dimitriou I, Chatzis I, Katsourakis A. The Main Anatomic Variations of the Hepatic Artery and Their Importance in Surgical Practice: Review of the Literature. J Clin Med Res. 2017;9(4):248-252. doi:10.14740/jocmr2902w.

19. PalliseraA,MoralesR, RamiaJM.Tricksand tipsin pancreatoduodenectomy. WorldJ GastrointestOncol.2014;6(9):344-350.doi:10.4251/wjgo.v6.i9.344.

20. Patel H, Chaudhary N, Nundy S. Pancreaticoduodenectomy: Techniques and controversies. Curr Med Res Pract. 2014;4(6):274-283. doi:10.1016/j. cmrp.2014.11.007.

21. Sabesan A, Gough BL, Anderson C, Abdel-Misih R, Petrelli NJ, Bennett $J$ J. High volume pancreaticoduodenectomy performed at an academic community cancer center. Am J Surg. October 2018. doi:10.1016/j. amjsurg.2018.10.041.

22. SantosPV, etal.Anatomicalvariationsoftheceliactrunk:asystematicreview. ABCD Arq Bras Cir Dig (São Paulo). 2018;31(4):e1403. doi:10.1590/0102$672020180001 \mathrm{e} 1403$

23. Strobel O, Neoptolemos J, Jäger D, Büchler MW. Optimizing the outcomes of pancreatic cancer surgery. Nat Rev Clin Oncol. October 2018. doi:10.1038/s41571-018-0112-1.

24. SulpiceL, RayarM, PaquetC, etal.Doesanaberrantrighthepaticarteryreally influencetheshort-andlong-term results ofa pancreaticoduodenectomy for malignant disease? A matched case-controlled study. J Surg Res. 2013;185(2):620-625. doi:10.1016/j.jss.2013.07.015.

25. Whipple AO, Parsons WB, Mullins CR. Treatment of carcinoma of the ampulla of vater. Ann Surg. 1935;102(4):763-779. http://www.ncbi.nlm. nih.gov/pubmed/17856666. Accessed January 1, 2019.

26. Zagyapan R, Kurkcuoglu A, Bayraktar A, Pelin C, Aytekin C. Anatomic variations of the celiac trunk and hepatic arterial system with digital subtraction angiography. Turkish J Gastroenterol. 2015;25(1):104-109. doi:10.5152/tjg.2014.5406 